\title{
A study on bacterial vaginosis in pregnancy and its effect on pregnancy outcome
}

\author{
Sai Deepthi Chikicherla*, V. Sitalakshmi
}

Department of Obstetrics and Gynecology, Narayana Medical College and Hospital, Nellore, Andhra Pradesh, India

Received: 13 May 2019

Accepted: 11 June 2019

\section{*Correspondence:}

Dr. Sai Deepthi. Chikicherla,

E-mail: dr.c.deepthi@gmail.com

Copyright: () the author(s), publisher and licensee Medip Academy. This is an open-access article distributed under the terms of the Creative Commons Attribution Non-Commercial License, which permits unrestricted non-commercial use, distribution, and reproduction in any medium, provided the original work is properly cited.

\begin{abstract}
Background: Bacterial vaginosis is an extremely prevalent vaginal condition and one of the causes of vaginitis among both pregnant and non pregnant women and associated with severe sequelae. Fifty percent of the women are asymptomatic. Current studies have found that the prevalence of BV ranges from $15 \%$ to $30 \%$ among non-pregnant women and $10 \%$ to $41 \%$ among pregnant women.

Methods: This is a prospective study conducted among 150 pregnant women who attended the antenatal outpatient and inpatient clinic in the Department of Obstetrics and Gynaecology at Narayana Medical College and Hospital, Nellore over a period of two years from Oct 2016 to Oct 2018. Obstetric cases fulfilling the inclusion and exclusion criteria were enrolled in the study by convenient sampling technique. They were followed till the outcome of pregnancy. The data was subjected to usual statistical analysis by employing the chi-square tests.

Results: Prevalence of the bacterial vaginosis was $20 \%$ in the present study. BV was significantly $(\mathrm{p}<0.05)$ associated with preterm delivery, PPROM, low birth weight, low APGAR and neonatal jaundice. Neonatal sepsis and congenital abnormalities showed no statistically significant difference $(\mathrm{p}>0.05)$ between BV positive and negative women.

Conclusions: Considering the vast spectrum of maternal and fetal morbidity associated with this infection, and the availability of rapid inexpensive diagnostic tests it may be prudent to screen BV in pregnancy, so that it may be treated early and hence prevent the adverse pregnancy outcomes.
\end{abstract}

Keywords: Bacterial vaginosis, Low birth weight, Low APGAR, Neonatal jaundice, PPROM, Preterm delivery

\section{INTRODUCTION}

Bacterial vaginosis is an extremely prevalent vaginal condition and one of the causes of vaginitis among both pregnant and non pregnant women and associated with severe sequelae. ${ }^{1}$ Fifty percent of women are asymptomatic. The classic symptom of $\mathrm{BV}$ is fowl smelling greyish white vaginal discharge.

Current studies have found that the prevalence of BV ranges from $15 \%$ to $30 \%$ among non-pregnant women and $10 \%$ to $41 \%$ among pregnant women. ${ }^{2}$ It is a complex alteration of the vaginal ecosystem, characterized by a shift in the vaginal flora from the normally predominant Lacto bacilli to overgrowth of mixed flora, including Gardenella Vaginalis, Mobiluncus, Provotella, Bacteroides and Mycoplasma species. ${ }^{3}$ BV results in an elevated $\mathrm{pH}$, increased vaginal fluid concentration of diamines, polyamines, organic acids, as well as enzymes such as mucinase, sialidase, IgA, proteases, collagenase, phospholipase A2 and C, endotoxin, cytokine, interleukin $1-\alpha$ and prostaglandins $\mathrm{E} 2$ and F2 $\alpha$. It is likely that these enzymes and organic compounds serve to overcome host defence mechanisms, facilitate the entrance of cervicovaginal microorganisms into the upper reproductive tract and contribute to the 
initiation of associated complications like preterm labour, spontaneous abortion, premature rupture of membranes, preterm premature rupture of membranes, chorioamnionitis, postpartum endometritis, post caesarean wound infection and neonatal complications. ${ }^{4}$

The recent awareness of the possible adverse sequelae of $\mathrm{BV}$ during pregnancy has led to more attention to screening and treating women during pregnancy. Also, the availability of more rapid, easier and less expensive tests have made it easier to screen the pregnant women.

The aims and objectives of this study are to study the incidence and risk factors of $\mathrm{BV}$ in pregnancy and to assess the feto-maternal outcome at Narayana Medical College and Hospital, Nellore for a period of 2 years.

\section{METHODS}

This prospective study was conducted among 150 pregnant women who attended the antenatal outpatient and inpatient clinic of the Department of Obstetrics and Gynaecology at Narayana Medical College Hospital, Nellore over a period of two years (October 2016 to October 2018).

Obstetric cases fulfilling the inclusion and exclusion criteria were enrolled in the study by convenient sampling technique. They were followed till the outcome of pregnancy. The data was subjected to usual statistical analysis by employing the chi-square tests.

\section{Inclusion criteria}

- All pregnant women who visited the antenatal clinic at Narayana Medical College and Hospital with or without symptoms, irrespective of age, parity and period of gestation will be screened for BV after due informed consent.

\section{Exclusion criteria}

- All pregnant women in labor

- Antimicrobial therapy in preceding two weeks

- History of cervical incompetence and cervical surgery

- History of antepartum hemorrhage, polyhydramnios, urinary tract infection, diarrhea or any other obvious cause of preterm labor

- Multiple pregnancy

- Intrauterine growth restriction, intrauterine death

- History of leaking per vagina or absent membranes

- Medical complications of pregnancy such as moderate to severe anemia, diabetes mellitus or any other maternal medical diseases

- History of known Mullerian anomalies

- A recent history of prenatal diagnostic procedures like cordocentesis, amniocentesis
- A detailed history was taken using a standardized proforma with particulars about age, parity, socioeconomic status. A thorough general and systemic examination was done to exclude exclusion criteria. A detailed obstetrical examination was done to note the fundal height, abdominal girth, presentation, uterine contractions, and fetal heart rate.

A clinical diagnosis was done based on Amsel's criteria followed by the microscopic examination including gram staining and culture for the accurate assessment of BV.

\section{Amsel's criteria}

Presence of three out of four following clinical criteria. ${ }^{5}$

- Homogeneous, thin, grey/ white vaginal fluid that adheres to vaginal walls

- Vaginal fluid $\mathrm{pH}>4.5$

- The release of fishy odour on addition of $\mathrm{KOH}$ to vaginal secretions, "Whiff test"

- Presence of vaginal epithelial cells with borders obscured with adherent, small bacteria called "clue" cells (>20\%) on wet mount preparation.

Of these four clinical criteria, the presence of clue cells on saline wet mount examination is the single most specific and sensitive indicator of $\mathrm{BV}$. Identification of clue cells accurately predicts 85 to $90 \%$ of women with clinical BV. ${ }^{6}$

\section{The appearance of vaginal discharge}

Per speculum examination is performed. A speculum is introduced into the vagina without lubricating with any antibacterial agent containing cream. The blade is opened and the appearance of vaginal discharge is seen. A homogenous, thin vaginal fluid that adheres to the vaginal walls is diagnostic of $\mathrm{BV}$.

\section{Vaginal fluid $p H$}

Normal vaginal $\mathrm{pH}$ is $3.8-4.2$. The $\mathrm{pH}$ was measured by using Cardinal $\mathrm{pH}$ indicator strips with a range of 3.6 to 6.1 with distinct colour codes for 3.6, 4.1, 4.4, 4.7, 5.0, $5.3,5.6$, and 6.1. The sample is obtained from the lateral vaginal wall or posterior fornices avoiding contamination with the cervical mucus using dipstick with the help of speculum withdrawn and matched with the scale provided.

\section{Whiff test}

The release of fishy or Amine odour with alkalinisation of vaginal fluid. 2 to 3 drops of $10 \%$ potassium hydroxide was added to the vaginal discharge on the speculum and sniff the mixture. The test is interpreted as positive if a fishy aroma is noted. 
Clue cells by wet mount preparation

Presence of vaginal epithelial cells with borders obscured with small adherent bacteria called "clue cells". Microscopic examination of a saline wet mount preparation of vaginal discharge is done. A drop of discharge was mixed with a drop of normal saline on a glass slide, covered with a clean cover slip and examined under a high power for the presence of epithelial cells, clue cells, pus cells Trichomonas vaginalis and Candida.

\section{RESULTS}

\section{Incidence of $B V$}

During the study period (2 years), among 150 pregnant women, 30 were diagnosed to have $\mathrm{BV}$ and the incidence is $20 \%$. (Figure 1 ).

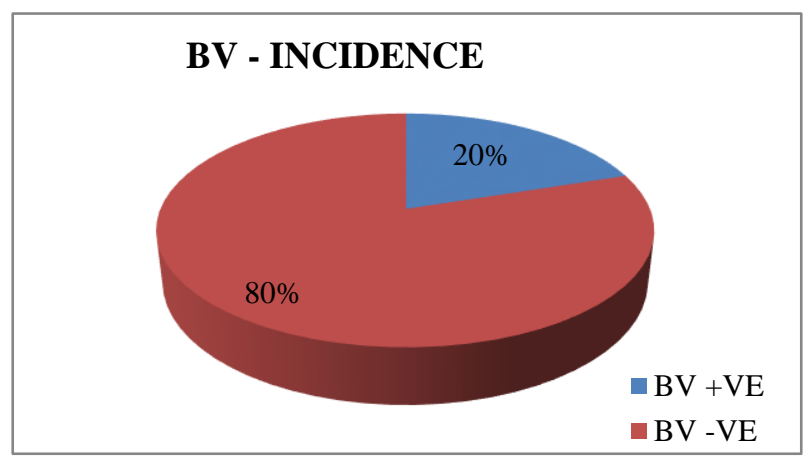

Figure 1: Incidence of BV among study population.

In the present study, age distribution varied from 18 - 36 years. BV is found significantly more among the younger age group (18 to $20 \mathrm{yrs}$ ). There is no actual correlation between age and BV (Table 1).

Table 1: Age distribution among study population.

\begin{tabular}{|lllll|}
\hline BV & n/t & $\begin{array}{l}\text { Mean } \\
\text { age }\end{array}$ & $\begin{array}{l}\text { Standard } \\
\text { deviation }\end{array}$ & T \\
\hline Positive & $30 / 150$ & 20.6333 & 2.77282 & 1.74500 \\
\hline Negative & $120 / 150$ & 23.9750 & 3.97146 & $\mathrm{p}=0.023$ \\
\hline $\mathrm{p}=0.023$, significant. & & & \\
\hline
\end{tabular}

\section{Relation between parity and $\mathrm{BV}$}

In the present study, $73.3 \%$ were primigravida with a pvalue 0.016 which is significant. In $\mathrm{BV}+\mathrm{ve}$ women, $16.7 \%$ were Gravida 2, and $10 \%$ were multigravida. But parity has no direct relationship with BV (Table 2).

\section{Distribution of study population based on SES}

In the present study, $63.4 \%$ of $\mathrm{BV}+\mathrm{ve}$ women belong to low SES (Class IV and V) based on modified Kuppuswamy scale, as most of the study population belong to rural areas (Table 3).
Table 2: Distribution of study population based on parity.

\begin{tabular}{|lllll|}
\hline Parity & B V positive & \multicolumn{2}{l|}{ B V negative } \\
\hline & n/t & $\mathbf{\%}$ & $\mathbf{n} / \mathbf{t}$ & $\mathbf{\%}$ \\
\hline Primi & $22 / 30$ & 73.3 & $53 / 120$ & 44.2 \\
\hline Gravida 2 & $5 / 30$ & 16.7 & $45 / 120$ & 37.5 \\
\hline Multigravida & $3 / 30$ & 10 & $22 / 120$ & 18.3 \\
\hline
\end{tabular}

$x 2=9.938 ; \mathrm{p}=0.016$, significant.

Table 3: Distribution of study population based on SES.

\begin{tabular}{|lllll|}
\hline SES & B V +ve & B V -ve \\
\hline & $\mathbf{n} / \mathbf{t}$ & $\mathbf{\%}$ & $\mathbf{n} / \mathbf{t}$ & $\mathbf{\%}$ \\
\hline Class I & $0 / 30$ & 0 & $22 / 120$ & 18.3 \\
\hline Class II & $4 / 30$ & 13.3 & $44 / 120$ & 36.7 \\
\hline Class III & $7 / 30$ & 23.3 & $29 / 120$ & 24.2 \\
\hline Class IV & $11 / 30$ & 36.7 & $15 / 120$ & 12.5 \\
\hline Class V & $8 / 30$ & 26.7 & $10 / 120$ & 8.3 \\
\hline
\end{tabular}

\section{Mean gestational age for swab test}

A vaginal swab was taken to all antenatal women irrespective of gestational age to screen BV. The mean gestational age at which swab was taken did not differ significantly between BV + ve and - ve women (Table 4).

Table 4: Distribution of study population based on mean gestational age at which swab was taken.

\begin{tabular}{|lllll|}
\hline BV & n/t & Mean & $\begin{array}{l}\text { Standard } \\
\text { deviation }\end{array}$ & T \\
\hline Positive & $30 / 150$ & 29.0667 & 6.83265 & 0.17800 \\
\hline Negative & $120 / 150$ & 28.7750 & 8.29444 & $\mathrm{p}=0.859$ \\
\hline
\end{tabular}

\section{Incidence of preterm labour among study population}

In the present study, $30 \%$ of $\mathrm{BV}+\mathrm{ve}$ women had preterm labour and $8.3 \%$ of $\mathrm{BV}$-ve women had preterm labor. $70 \%$ of BV +ve and $91.7 \%$ of BV-ve had term delivery. Preterm labor is significantly $(\mathrm{p}<0.001)$ more common with BV (Table 5).

Table 5: Preterm and term deliveries among study population.

\begin{tabular}{|lllll|}
\hline & BV+ve & \multicolumn{3}{l|}{ B V -ve } \\
\hline & $\mathbf{n} / \mathbf{t}$ & $\mathbf{\%}$ & $\mathbf{n} / \mathbf{t}$ & $\mathbf{\%}$ \\
\hline Preterm & $9 / 30$ & 30 & $10 / 120$ & 8.3 \\
\hline Term & $21 / 30$ & 70 & $110 / 120$ & 91.7 \\
\hline
\end{tabular}

$\varkappa 2=10.185, \mathrm{p}<0.001$ very highly significant.

\section{Incidence of PPROM in study population}

In this study, $36.6 \%$ of BV +ve women had PPROM and only 5.84 of BV -ve had PPROM. The incidence of 
PPROM is statistically significant in BV +ve women with a p value of 0.004 (Table 6).

Table 6: Incidence of PPROM in BV positive and negative women.

\begin{tabular}{|lllll|}
\hline PPROM & $\mathrm{Bv}+\mathrm{ve}$ & \multicolumn{3}{c|}{$\mathrm{Bv}-\mathrm{ve}$} \\
\hline & $\mathbf{n} / \mathbf{t}$ & $\mathbf{\%}$ & $\mathbf{n} / \mathbf{t}$ & $\mathbf{\%}$ \\
\hline Positive & $11 / 30$ & 36.66 & $7 / 120$ & 5.84 \\
\hline Negative & $19 / 30$ & 63.33 & $113 / 120$ & 94.16 \\
\hline $\boldsymbol{x} 2=8.507 ; \mathrm{p}=0.004$ highly significant.
\end{tabular}

\section{Incidence of PROM in study population}

In the present study, only $10 \%$ with BV had PROM, with a p-value 0.20 , which is not significant. $7.5 \%$ of $B V-v e$ women had PROM (Table 7).

Table 7: Incidence of PROM in BV positive and negative women.

\begin{tabular}{|lllll|}
\hline PROM & $\mathrm{Bv}+\mathrm{ve}$ & \multicolumn{3}{c|}{$\mathrm{Bv}-\mathrm{ve}$} \\
& $\mathbf{n} / \mathbf{t}$ & $\mathbf{\%}$ & $\mathbf{n} / \mathbf{t}$ & $\mathbf{\%}$ \\
\hline Positive & $3 / 30$ & 10 & $9 / 120$ & 7.5 \\
\hline Negative & $27 / 30$ & 90 & $111 / 120$ & 92.5 \\
\hline
\end{tabular}

$\varkappa 2=0.204 ; \mathrm{p}=0.652$, not significant.

\section{Mode of delivery among study population}

$20 \%$ of BV had PTVD, $53.3 \%$ had FTVD, $10 \%$ had EMLSCS (Indication - failed induction and fetal distress), $6.7 \%$ had ELLSCS (Indication - Repeat LSCS with CPD and contracted pelvis, malpresentation, malposition), and $10 \%$ had instrumental delivery. Among which, PTVD is highly significant in BV (Table 8).

Table 8: Mode of delivery in BV positive and negative women.

\begin{tabular}{|lllll|}
\hline $\begin{array}{l}\text { Mlode of } \\
\text { delivery }\end{array}$ & BV +ve & & BV -ve \\
\hline & $\mathbf{n} / \mathbf{t}$ & $\mathbf{\%}$ & $\mathbf{n} / \mathbf{t}$ & $\mathbf{\%}$ \\
\hline FTVD & $16 / 30$ & 53.3 & $84 / 120$ & 70 \\
\hline PTVD & $6 / 30$ & 20 & $8 / 120$ & 6.7 \\
\hline EMLSCS & $3 / 30$ & 10 & $18 / 120$ & 15 \\
\hline ELLSCS & $2 / 30$ & 6.7 & $4 / 120$ & 3.3 \\
\hline FORCEPS & $3 / 30$ & 10 & $6 / 120$ & 5 \\
\hline$x 2=13.50 \mathrm{p}=<0.002$, significant. & & \\
\hline
\end{tabular}

\section{Incidence of low birth weight among study population}

Birth weight is significantly less among patients with BV. The mean B.wt in BV+ve is 2.45. The lower birth weight associated with BV could have been because of lower gestational age at birth in BV positive patients. Therefore an ANCOVA test was performed to see whether b.wt still differed between BV positive and negative patients after convariating the effect of gestational age at birth and found to be statistically significant (Table 9).
Table 9: Incidence of low birth weight in BV positive and negative women.

\begin{tabular}{|lllll|}
\hline \multicolumn{1}{|c}{ BV } & $\mathrm{n} / \mathrm{t}$ & Mean & $\begin{array}{l}\text { Standard } \\
\text { deviation }\end{array}$ & $\mathrm{T}$ \\
\hline Positive & $30 / 150$ & 2452.0000 & 537.09564 & 1.14600 \\
\hline Negative & $120 / 150$ & 2868.2500 & 486.74647 & $\mathrm{p}=0.0254 \mathrm{~s}$ \\
\hline
\end{tabular}

\section{Incidence of low APGAR at birth among study population}

The mean APGAR is 5.133 in $\mathrm{BV}$ +ve and 7.45 in BV ve women. APGAR is significantly lower $(p=0.004)$ in $\mathrm{BV}$ positive patients may be due to preterm delivery, low b.wt and early onset of neonatal sepsis (Table 10).

Table 10: Incidence of low APGAR at birth in BV positive and negative women.

\begin{tabular}{|lllll|}
\hline BV & $\mathrm{n} / \mathrm{t}$ & Mean & $\begin{array}{l}\text { Standard } \\
\text { deviation }\end{array}$ & $\mathrm{T}$ \\
\hline Positive & $30 / 150$ & 5.1333 & 1.35782 & 1.24200 \\
\hline Negative & $120 / 150$ & 7.4583 & 1.26289 & $\mathrm{p}=0.004 \mathrm{~s}$ \\
\hline
\end{tabular}

\section{Incidence of congenital abnormalities in study population}

$3.33 \%$ of $\mathrm{BV}+\mathrm{ve}$ and $1.7 \%$ of $\mathrm{BV}-\mathrm{ve}$ women had Cong. abnormalities. It did not differ significantly between BV positive and negative patients (Table 11).

Table 11: Incidence of congenital abnormalities in BV positive and negative women.

\begin{tabular}{|l|llll|}
\hline Cong abn. & Bv + ve & Bv -ve \\
& $\mathbf{n} / \mathbf{t}$ & $\mathbf{\%}$ & $\mathbf{n} / \mathbf{t}$ & $\mathbf{\%}$ \\
\hline Positive & $1 / 30$ & 3.33 & $2 / 120$ & 1.7 \\
\hline Negative & $29 / 30$ & 96.6 & $118 / 120$ & 98.3 \\
\hline
\end{tabular}

« $2=2.312 ; \mathrm{p}=0.128$, not significant

\section{Incidence of neonatal jaundice among study population}

In the analysis, $50 \%$ of $\mathrm{BV}+\mathrm{ve}$ and $30 \%$ of $\mathrm{BV}-\mathrm{ve}$ had neonatal jaundice. It is significantly found to be more in $\mathrm{BV}$ positive women with a p-value of 0.039 . But when it is analyzed separately among term and preterm babies in $\mathrm{BV}$ positive and negative women, there is no statistically significant difference $(\mathrm{p}=0.072)$ (Table 12).

Table 12: Incidence of neonatal jaundice in BV positive and negative women.

\begin{tabular}{|lllll|}
\hline Neo. Jaundice & $\mathrm{Bv}+\mathrm{ve}$ & $\mathrm{Bv}-\mathrm{ve}$ \\
\hline & $\mathbf{n} / \mathbf{t}$ & $\mathbf{\%}$ & $\mathbf{n} / \mathbf{t}$ & $\mathbf{\%}$ \\
\hline Positive & $15 / 30$ & 50 & $36 / 120$ & 30 \\
\hline Negative & $15 / 30$ & 50 & $84 / 120$ & 70 \\
\hline
\end{tabular}

$\varkappa 2=4.278 ; \mathrm{p}=0.039$ significant. 
Table 13: Incidence of neonatal jaundice in BV positive and negative women.

\begin{tabular}{|lllll|}
\hline Early neo.sepsis & \multicolumn{2}{c}{ Bv + ve } & Bv -ve \\
\hline & $\mathbf{n} / \mathbf{t}$ & $\mathbf{\%}$ & $\mathbf{n} / \mathbf{t}$ & $\mathbf{\%}$ \\
\hline Positive & $4 / 30$ & 13.3 & $5 / 120$ & 4.2 \\
\hline Negative & $26 / 30$ & 86.6 & $115 / 120$ & 95.8 \\
\hline $\boldsymbol{x}^{2}=0.337 ; \mathrm{p}=0.046$, significant. & & \\
\hline
\end{tabular}

\section{Incidence of early neonatal sepsis among study population}

In the analysis, $13.3 \%$ of $\mathrm{BV}+\mathrm{ve}$ and $4.2 \%$ of $\mathrm{BV}-\mathrm{ve}$ women had early neonatal sepsis. It was significantly associated with BV positive women (Table 13).

\section{Incidence of puerperal sepsis among study population}

In the present study, $3.3 \%$ of $\mathrm{BV}+\mathrm{e}$ and $0.8 \%$ of $\mathrm{BV}-\mathrm{ve}$ women had puerperal sepsis. Puerperal sepsis did not differ significantly $(\mathrm{p}=0.361)$ between $\mathrm{BV}$ positive and negative women (Table 14).

Table 14: Incidence of puerperal sepsis in BV positive and negative women.

\begin{tabular}{|lllll|}
\hline Puerperal sepsis & Bv + ve & \multicolumn{3}{l|}{ Bv -ve } \\
\hline & $\mathbf{n} / \mathbf{t}$ & $\mathbf{\%}$ & $\mathbf{n} / \mathbf{t}$ & $\mathbf{\%}$ \\
\hline Positive & $1 / 30$ & 3.3 & $1 / 120$ & 0.8 \\
\hline Negative & $29 / 30$ & 96.7 & $119 / 120$ & 99.2 \\
\hline$x 2=0.458 ; \mathrm{p}=0.361$, not significant. & & \\
\hline
\end{tabular}

\section{Mode of onset of labour among study population}

In $\mathrm{BV}+\mathrm{ve}$ women, $60.7 \%$ had spontaneous onset of delivery, and $39.2 \%$ were induced. In BV -ve women, $71.5 \%$ had spontaneous, and $28.4 \%$ were induced. Mode of onset of labour did not differ significantly between BV positive and negative women (Table 15).

Table 15: Mode of onset of labour in BV positive and negative women.

\begin{tabular}{|lllll|}
\hline Onset of labour & B V +ve & BV -ve \\
\hline Spontaneous & $\mathbf{n} / \mathbf{t}$ & $\mathbf{\%}$ & $\mathbf{n} / \mathbf{t}$ & $\mathbf{\%}$ \\
\hline Induced & $17 / 28$ & 60.7 & $78 / 109$ & 71.5 \\
\hline
\end{tabular}

« $2=1.467 ; \mathrm{p}=0.226$, not significant.

\section{DISCUSSION}

Bacterial vaginosis is a polymicrobial syndrome and one of the common causes of vaginal discharge, but $50 \%$ are asymptomatic. Studies round the world demonstrate that $\mathrm{BV}$ in pregnancy is associated with maternal and neonatal morbidity. ${ }^{7}$ Preterm delivery is the major cause of perinatal morbidity and mortality. The etiology is multifactorial, but there is now substantial evidence that infection ascending into the uterine cavity from the lower genital tract is associated with idiopathic preterm labour. ${ }^{8}$

The incidence varies in different population in different clinical situations. Overall the incidence of $\mathrm{BV}$ in antenatal women ranges from $10 \%-41 \% .{ }^{9}$ In the present study, the incidence of BV was $20 \%$ corresponding to the quoted incidence and correlates with the studies done by Gravett et al. (19\%), Kurki et al $(21.5 \%)$ and Pastore et al $(17.5 \%)$.

In the studies done by Helaye et al, and Kurki et al, there was no significant relationship between mean age and $\mathrm{BV}$, as most of the study group belonged to the urban population with late marriages.

But in the present study, we observed a statistically significant difference in age group $(\mathrm{p}=0.023)$. These high figures in the young women (age 18 to 20 years) may be due to the practice of early marriages in the present study population, especially in the rural sector with low SES.

Helaye et al, Gravett et al, and Kurki et al, found no significant difference in the parity and demographic factors in BV positive and negative group. In the present study $73.33 \%$ of BV +ve women are primigravida, with a statistically significant difference $(p<0.016)$, though there is no direct relationship between $\mathrm{BV}$ and parity.

In the study done by Gravett et al, $20.58 \%$ of BV +ve women belong to low SES with no statistically significant difference. In the present study, $63.33 \%$ of $\mathrm{BV}+\mathrm{ve}$ women belong to low SES which is statistically significant $(p<0.001)$. Majority of patients in the present study are from the rural sector with poor personal hygiene, that causes an alteration in the composition of normal vaginal flora leading to $\mathrm{BV}$.

In the studies done by Kurki et al, Gravett et al, Jacobsson et al, Mathew et al, Purwar et al, demonstrated significant risk of PTL in BV +ve women. The incidence of PTL in the present study was $30 \%$ and highly significant $(\mathrm{p}<0.001)$ that corresponds with the studies done by Jacobsson et al. and Purwar et al, (32\% and $28.88 \%$ respectively).

Kurki et al, and James Mc Gregor et al, reported in their study that PPROM was significantly high in BV positive women ( $p<0.006)$. Purwar et al. also reported an incidence of $11.1 \%$ of PPROM ( $p=0.001$ ) in BV positive women. In the present study the incidence of PPROM is $13.3 \%$ and is close to the study done by Purwar et al. The cause of PPROM is a reduction in membrane tensile strength due to the effect of bacterial proteases and repeated stretching caused by uterine contractions.

Gravett et al, demonstrated LBW among BV positive women $(p=0.004)$. In the present study, the incidence of LBW correlates with the study done by Gravett et al. 
With respect to either Amsel's criteria comparing sensitivity, specificity, and PPV, the isolation of G.vaginalis from culture was less than the gram stain to diagnose BV.

The method used for diagnosis of BV is not uniform in all studies. However, a majority of the studies have reported a high degree of correlation between clinical criteria for diagnosis and laboratory methods. Thus in our study, we used a combination of Amsel's criteria and Gram stain (Nugent's criteria) for the diagnosis of BV in pregnancy.

Various studies have shown that treatment with metronidazole in $\mathrm{BV}$ positive pregnant women is associated with a significant decrease in maternal and fetal morbidity. Hence there may be a role for screening BV in pregnancy at booking visit. Clinical criteria along with Gram stain which is a simple procedure can be used for diagnosis instead of sophisticated lab techniques. Early treatment of BV positive individual may reduce the morbidity due to this condition.

Treating BV positive pregnant women at high risk of preterm delivery has now challenged by more recent evidence. The evidence to date suggests that there is no role for antibiotic therapy in low-risk pregnant women who have BV. ${ }^{10}$ Given our current knowledge, the treatment of $\mathrm{BV}$ in pregnancy or just before conception will be beneficial.

\section{CONCLUSION}

Vaginal milieu at various gestational ages is not different. Hence screening for $\mathrm{BV}$ at the first trimester of pregnancy is a representative of the vaginal milieu in all trimesters. The clinical method using Amsel's criteria in combination with Gram stain is a simple, inexpensive, easily reproducible, method for diagnosis and can be used on a mass scale. BV in pregnancy is associated with significant risk of preterm labor and PROM. Fetal morbidity in terms of low birth weight, low APGAR and neonatal Jaundice is significantly higher among BV positive pregnant women, and this is possible because of lower gestational age at birth. So, Universal screening of all pregnant women at the booking visit may be recommended to initiate treatment in symptomatic women and those with high risk for preterm delivery.
Funding: No funding sources

Conflict of interest: None declared

Ethical approval: The study was approved by the Institutional Ethics Committee

\section{REFERENCES}

1. Tanuja C, Patel DA, Gupta PA. Aetilogy of preterm labour in bacterial vaginosis. J Obstet Gynecol India. 2008;58(5):402-5.

2. Eschenbach DA, Hillier S1, Critchlow C. Diagnosis and clinical manifestations of bacterial vaginosis. Am J Obstet Gynecol. 1988;158:819.

3. Tripathia R, DiMaria $\mathrm{S}$, Bhallab $\mathrm{P}$, Ramji $\mathrm{S}$. Bacterial vaginosis and pregnancy outcome. Int $\mathbf{J}$ Gynaecol Obstet. 2003;83:193-5.

4. McDonald HM, O'Loughlin JA, Jolley P, Vigneswaran R, Mc Donald PJ. Vaginal infection and preterm labor. $\mathrm{Br} \mathrm{J}$ Obstet Gynecol. 1991;98:427-35.

5. Fernando A. Preterm labor practical guide to highrisk pregnancy and delivery. 4th Edition:71-96.

6. Main DM. Epidemiology of preterm birth. Clin $\mathrm{Ob}$ Gynecol. 1988;31:521-32.

7. Oleen-Burkey MA, Hillier SL. Pregnancy complications associated with bacterial vaginosis and their estimated costs. Obstet Gynecol. 1995;3:14957.

8. Nugent RP, Krohn MA, Hillier SL. Reliability of diagnosing bacterial vaginosis is improved by a standardized method of Gram stain interpretation. J Clin Microbiol. 1991;29:297-301.

9. Tapio K, Aulikki S, Olavi Y. Bacterial vaginosis in early pregnancy and pregnancy outcome. Obstet Gynecol. 1992;80:173-7.

10. Centers for disease control. 1998 guidelines for treatment of sexually transmitted diseases. MMWR. 1997:47-8.

Cite this article as: Chikicherla SD, Sitalakshmi V. A study on bacterial vaginosis in pregnancy and its effect on pregnancy outcome. Int J Reprod Contracept Obstet Gynecol 2019;8:2826-31. 